\title{
Application Research of Computer-aided Teaching Based on Network in College English Teaching Reform
}

\author{
Xiaoxue Zhang ${ }^{1}$ \\ East China Normal University
}

\author{
Junnan Wang ${ }^{2}$ \\ Naval Medical University
}

\begin{abstract}
The entry of computer network technology into the field of foreign language teaching will of course change the information transmission channel of traditional foreign language teaching, the integration of teaching content and activities, and even the teaching process. It will also make a huge change in the structure of teaching structure and its constituent elements, and promote the change of teaching concepts, leading to changes in the value of teaching and evaluation criteria. This thesis is mainly aimed at exploratory research on the integration of computer network and foreign language teaching in college English teaching reform. The key point is to overcome the problems and confusions faced by foreign language teaching after integration, and to explain the various aspects of integration by applying the applicable theory of foreign language teaching.
\end{abstract}

\section{Keywords}

English Teaching Reform • Computer Network • Computer-aided Teaching

\footnotetext{
${ }^{1}$ Correspondence to: Xiaoxue Zhang (PhD), School of Foreign Languages, East China Normal University, Shanghai 200241, China. Email: zxx@fudan.edu.cn

${ }^{2}$ Basic Medical College, Naval Medical University, Shanghai 200433, China. Email: 17521362620@163.com

Citation: Zhang, X.X., Wang, J.N. (2018). Application Research of Computer-aided Teaching Based on Network in
College English Teaching Reform. Educational Sciences: Theory \& Practice, 18(5), 1765-1774.
http://dx.doi.org/10.12738/estp.2018.5.076
}


The teaching practice model is based on a certain foreign language teaching theory, which can fully reflect the main points and practical principles of these theories (Kreskey \& Truscott, 2016; Islam, 2017; Svirko \& Mellanby, 2017). Over the years, there have been many theories in foreign language teaching, and there are countless others. For foreign language teaching, there are three teaching principles: 1) step-by-step input; 2) intensive learning style; 3) prompt feedback principle immediate feedback (Gan \& Balakrishnan, 2014; Lakin, Elliott \& Liu, 2012). According to these teaching principles, the teaching mode shown in Figure 1 is produced in foreign language teaching:

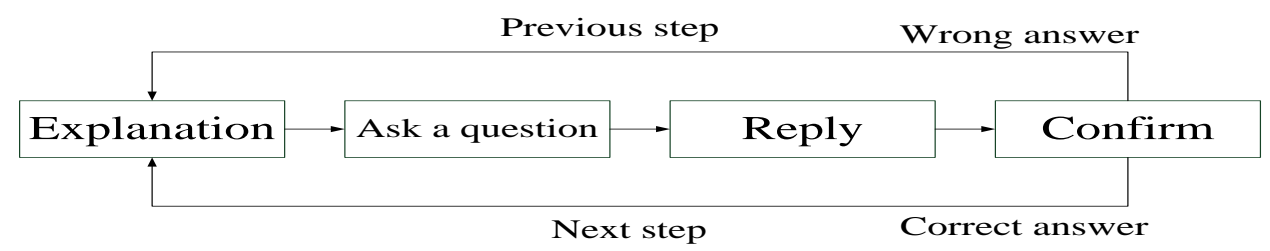

Figure 1. Teaching mode 1.

With regard to teaching principles and teaching models, the main point of cognitive theory is that cognitive theory emphasizes the various factors that arise between people's stimulation and reaction, because people are different and each person's perception is different (Ellis, Basturkmen \& Loewen, 2012; Arnal Wishnowski, Yu Pear, Chand, \& Saltel, 2018; Nicole, Jeremy, Geneva \& Jennifer, 2010). Their experience, education, age, gender, ambition, hobbies, and health are the same. Since perception is a highly selective process, different people will react differently to the same stimulus. Since perceptions are different and there may be epiphanies in the past, it is important to emphasize the learners' own findings in their studies (Hazavehei, Moonaghi, Moeini, Moghimbeigi \& Emadzadeh, 2015; Osagie, Wesselink, Blok, Lans \& Mulder, 2016). Since students need to carry out meaningful learning and drills, they must have the necessary social scenes so that communication can be carried out effectively and achieve the effect of language learning (Starrett, Doman, Garrison, \& Sleigh, 2015). In view of these principles, the teaching model in Figure 2 is produced:

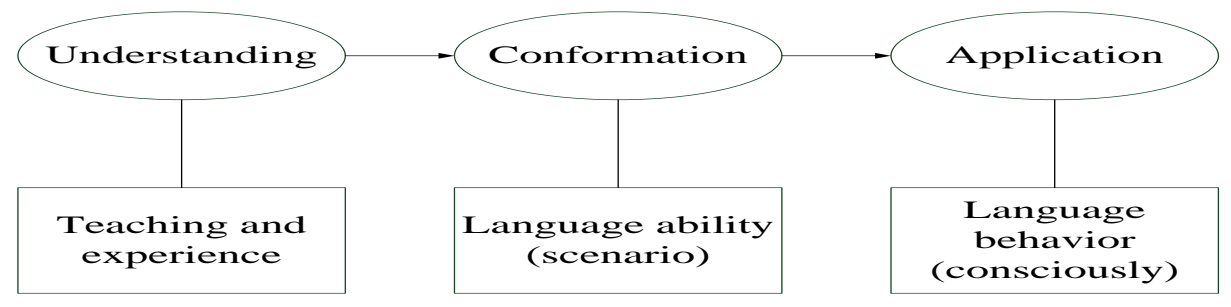

Figure 2. Teaching mode 2.

This model shows that foreign language learning has its own characteristics, different from the learning process of the mother tongue. The first is the different language environments. When learning foreign languages in the classroom, what students lack is the natural language environment. Learning depends on the learner's experience and cognitive level (Rosales, Gongola, \& Homlitas, 2015; Kreskey \& Truscott, 2016). Second, students learn foreign languages on the basis of mastering the mother tongue. In addition, learning foreign languages is conscious, conscious, and organized learning. According to the above characteristics, the cognitive 
teaching process is divided into three stages: cognitive understanding, formation and application (Zhang, 2017). Language understanding is to let students discover language rules under the guidance of teachers; language skills are mainly practiced through conscious and organized situations; language use stages must be separated from texts for specialized communicative exercises, such as some communicative exercises with context, etc. Making language behavior a true conscious behavior gradually enables learners to form active construction in their own learning (Liao, 2007). This laid the foundation for constructivist learning theory.

\section{Computer and English teaching}

\section{The new concept of computer applied to English teaching}

The first view is that with the rapid development of computer science, the role of computers in foreign language teaching has far exceeded its auxiliary functions. Computers have gradually moved from the auxiliary role to the foreground of teaching, that is, toward teaching. leading position. This view is mainly based on three aspects: 1) Computer-assisted foreign language teaching means that teachers use some functions of the computer (or let the computer share part of the teaching work) to improve the teaching methods and improve the teaching effect. In other words, the computer-aided object is the teaching staff, and the function of the computer must be realized through the operation of the teaching staff. If the initial computer-aided role is mainly reflected in "the means and methods to improve the teaching process, it will enhance the teaching ability of teachers." 2) The three key technologies of the computer, namely artificial intelligence technology, digital technology, and information network technology, have been rapidly obtained. development of. Artificial intelligence technology makes the computer's functions intelligent, and intelligent means that the computer can carry out anthropomorphic thinking and can play a human role in teaching. In this sense, the development of artificial intelligence technology has laid the foundation for the computer to move from auxiliary to leading. 3) In the field of foreign language learning, learners and computers have actually formed a human-machine society, as shown in Table 1:

Table 1

Man-machine Contrast

\begin{tabular}{lll}
\hline Computer technology development & \multicolumn{1}{c}{ Computer } & \multicolumn{1}{c}{ User } \\
\hline Mainframe & One computer & Many people \\
PC & One computer & One people \\
The internet & More than one computer & Many people \\
\hline
\end{tabular}

In this human-machine society, we can see such a human-machine correspondence: early years, large-scale computers were used in the field of foreign language teaching. Because of the high cost of machines, only timesharing methods can be used to enable many learners to share a computer at the same time. Resource sharing achieves economics, and learners and computers form a "multiple-person-one-machine" correspondence; when a PC appears, the machine is no longer expensive, and the learner can use a single computer, and the humanmachine forms "one person." • One machine" correspondence; since the emergence of the network (intelligent, digital), many learners can operate online at the same time, sharing the hardware, software and information 
resources of many networked computers, and the human-machine becomes "multi-person • multi-machine" Correspondence relationship. In fact, today's learners can have multiple microcomputers that are wirelessly networked so that anyone can get whatever they need, anywhere, anytime. Each learner can learn on demand, and the prototype of computer-led foreign language teaching has taken shape, as shown in Figure 3:

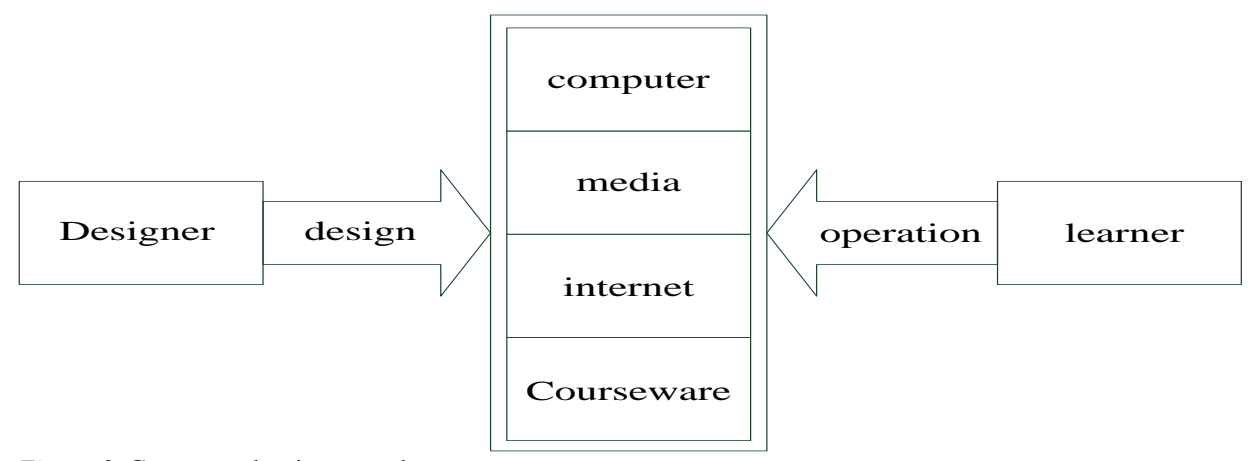

Figure 3. Computer dominant mode.

\section{Integration of Computer Network and English Teaching}

The integration of computer network and foreign language teaching is different from computer-aided teaching in essence: computer-assisted instruction is an auxiliary function, that is, assisting teachers to improve the effect of teaching, and after computer and teaching integration, it will become an organic component of the whole teaching system. Therefore, the integration of computer network and teaching has fundamentally changed the essence of teaching, mainly reflected in three aspects: breaking the limitations of "classroom + textbook", creating an ideal environment and method of teaching and learning, and fundamental changes in teaching structure.

Computer-assisted instruction is actually based on classrooms and textbooks, which means that textbooks are the only source of student knowledge, as shown in Figure 4:

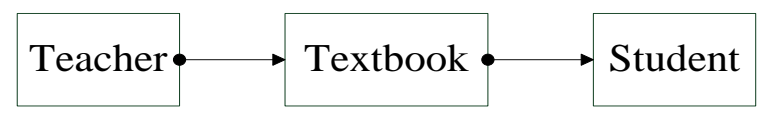

Figure 4. Textbook-based teaching.

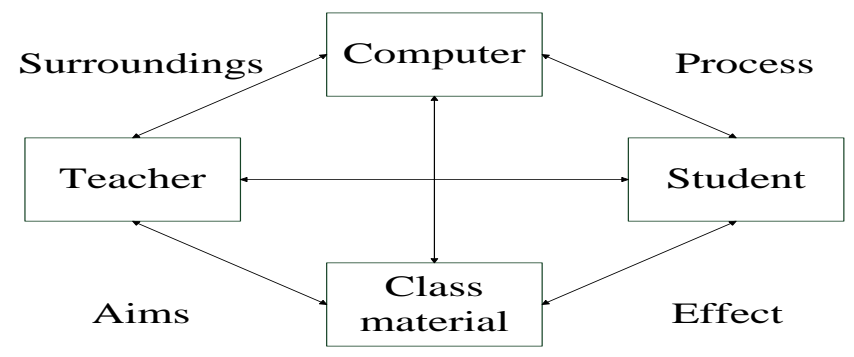

Figure 5. Computer and English teaching integration framework. 
The relationship between teachers, textbooks and students is the teacher's mastery of the classroom, and the knowledge is transmitted to students through the use, analysis and interpretation of textbooks. Textbooks are only a medium for communication between teachers and students. Students learn from the analysis and interpretation of textbooks by teachers. (Accept) knowledge. The essential feature of this model is that the teacher leads the teaching, the students are completely in a passive position, and become the object of being instilled in knowledge, even if the teacher uses the computer as an auxiliary tool for teaching.

The teacher only teaches the textbook knowledge to the students through computer demonstrations or explanations. The computer only enhances the teaching effect and means, but the traditional teaching form of the classroom + textbook is - and the situation that the textbook is the only source of knowledge of the students is not broken. However, computer network and curriculum integration can change this situation because the framework of teaching has undergone fundamental changes, as shown in Figure 5:

As far as the teaching elements are concerned, the relationship between teachers, students, computers and teaching content is not one-way, but two-way relationship of mutual connection, interaction, interdependence and mutual transformation. In this framework of computer and teaching integration, the role of teachers has undergone fundamental changes. They are no longer the centre of classroom teaching. Students are transformed from passive knowledge recipients to active constructors of knowledge, and students' knowledge sources are also single. The textbook paper media has expanded into numerous media.

\section{Survey on the implementation of the new model}

During the field trip, we conducted a major survey of University1 and University 2. University1 belongs to the national 985 key colleges, with strong teachers and good students. It is one of the pilot universities for teaching reform in the Ministry of Education. University2 is a local university (belonging to tier two colleges). The sources of teachers and students are relatively common. It is not a pilot institution for the reform of college English teaching in the Ministry of Education. We selected these two universities to conduct surveys in order to compare the similarities and differences between college English teaching between pilot and non-pilot colleges and try to find out the actual functions and functions of computer networks in foreign language teaching.

The survey was conducted in a combination of questionnaires and interviews. 40 students from University1 and University2 answered the questionnaire. The questionnaire mainly involves such aspects as: 1) classroom activities after the reform of college English teaching; 2) perceptions of the application of computer networks in teaching; 3) the role of computer networks and independent learning; 4) teacher role and computer network English teaching mode.

For the classroom activities of English teaching, we analyze the results in Table 2.

According to the results of the survey, the overall teacher and student classroom activities differed between the two schools due to different teachers and students, but the proportion of activities was basically the same. The above results can at least explain the fact that after the reform of college English teaching, China's higher 
education institutions (whether pilot or non-pilot colleges) have changed the traditional teaching methods to some extent, and have adopted modern information technology. (Computer, network, courseware, etc.) is applied to our foreign language teaching, and some traditional classroom activities (test activities, etc.) are relatively reduced.

Table 2

\begin{tabular}{lcc} 
The Main Activities of Teachers in the English Class & \\
\hline Item & University1 & University2 \\
\hline Use multimedia courseware to explain vocabulary, grammar, and translation & $83.34 \%$ & $78.49 \%$ \\
texts & $0.01 \%$ & $11.62 \%$ \\
Explain the fourth and sixth level simulation questions & $21.67 \%$ & $6.68 \%$ \\
Practice vocabulary, sentence pattern & $78.59 \%$ & $60.23 \%$ \\
Introduce chapter structure and cultural background knowledge with & & \\
multimedia courseware & $63.28 \%$ & $16.59 \%$ \\
Organize classroom activities such as student discussions, role & $3.15 \%$ & $3.16 \%$ \\
performances, and simulated situational dialogues & \\
Other
\end{tabular}

In summary, we believe that although the sample of classroom observation and student survey is not large, we can still draw such conclusions: 1) In the current college English teaching, colleges and universities are increasingly inclined to apply computer networks to the classroom. Teaching, but the computer is only an auxiliary tool, its comprehensive function has not been fully utilized and utilized in teaching; 2) Modern information technology with computer network as the core can improve the effectiveness and efficiency of foreign language teaching, but the extent of improvement Not very obvious; 3) When the computer network is fully applied to our English teaching, students have higher expectations for the role of teachers; 4) students generally recognize the teaching mode of "teacher-led-student subject", but based on computer Students in selfdirected learning do not seem to be doing enough and diversified, mainly because of the lack of learning resources and equipment construction. This is the current situation of computer and foreign language teaching in Chinese universities. Undoubtedly, the current state of teaching cannot contribute to the reform of college English teaching. It can't help the effective implementation of "computer-based and classroom English teaching mode", and it can't help the computer network and foreign language courses to truly integrate effectively. . In view of this, we believe that to change the status quo, we should first change the concept, change people's traditional views on computer and foreign language teaching, and at the same time understand the new concept of computer application in foreign language teaching.

\section{Informatization English teaching mode}

\section{Problem-based teaching model}

The problem-based teaching model should include such stages in contextual implementation: scenario creation and problem presentation, problem definition and problem analysis, inquiry and problem solving, division of labor cooperation and completion of tasks, evaluation and feedback. The first stage: scenario creation and problem presentation. Teachers should use various information technologies to propose guiding problems according to the real-time teaching content and requirements, and gradually form specific learning tasks. The questions raised should meet the following requirements: 1) to have a corresponding problem situation description, which can arouse students' interest; 2) the problem orientation should be clear, the learning focus 
should be clear, the implementation process should be clear; 3) the difficulty should be appropriate, Based on the premise of synthesizing original knowledge, exploring new knowledge is the main goal. On the basis of the questions raised, the students can further refine the tasks according to the learning priorities. The second stage: problem definition and problem analysis. After the problem is clear, students should use their own language to define and describe the problem to be studied according to their own understanding. The third stage: exploring and solving problems. After determining the assignment of learning tasks, information related to the topic is collected through various means, and the collected information is classified, organized, and analyzed.

When implementing the problem-based teaching mode, such an operating procedure can be followed, as shown in figure 6.

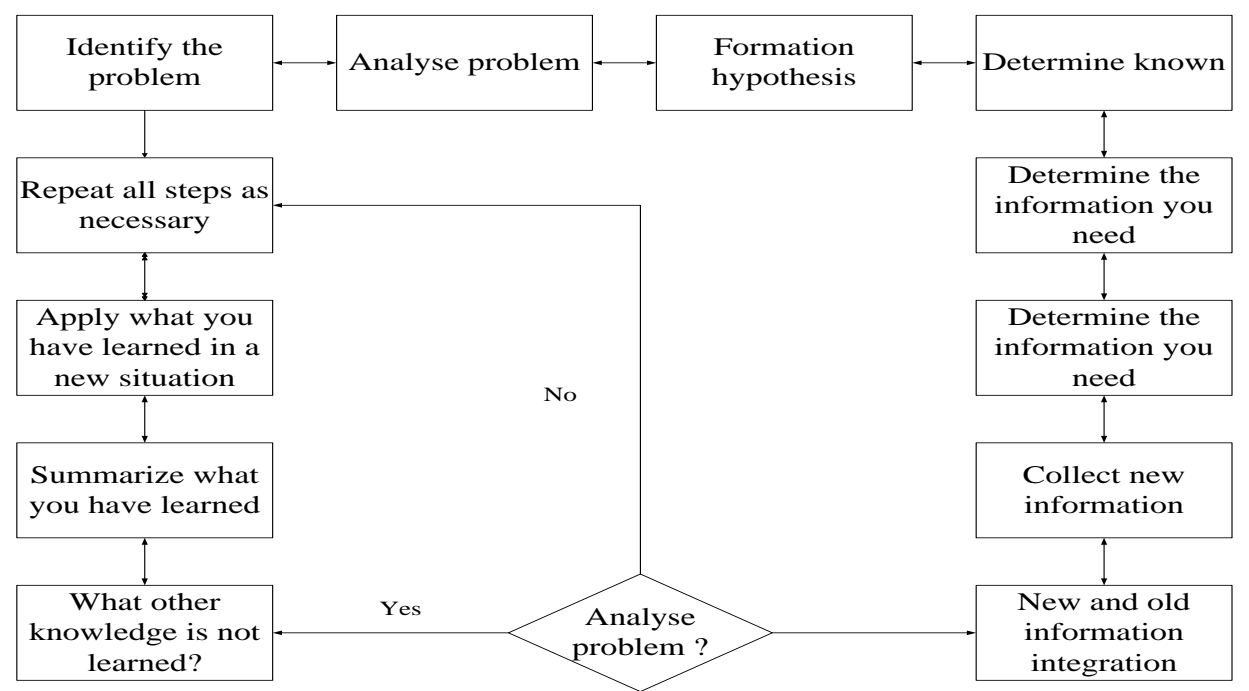

Figure 6. Operating procedure based on problem teaching mode.

\section{Fundamental changes in the structure of English teaching}

In this kind of teaching structure, teachers must change their role in the traditional sense, and must have a new understanding of the changes in the teaching structure. To do this, teachers first need to experience how to use the advantages of computers to acquire new knowledge. As we all know, in our country for many years, our foreign language teaching is carried out in traditional classrooms. In such an environment, teachers always explain, students listen or take notes. Classroom activities are nothing more than questions, key exercises, exams, etc. However, the dominant-subject teaching structure requires the integration of computers as an organic part of our foreign language teaching. Teachers have basically no experience to draw on.

In the new teaching structure, teachers must also let students use computer networks to construct or acquire new knowledge, so they must first experience the process of learning activities. This kind of experience not only helps teachers to understand the advantages of computers and the problems and frustrations students may encounter in their learning activities, but also helps teachers to carry out targeted and well-structured design 
work. Second, teachers need to use their knowledge of student learning and knowledge about computer functions to design, manage, and maintain a student-centered, multidimensional learning environment. With the integrated teaching experience of computers and courses, teachers can use the advantages of computers and combine the learning characteristics of students to design and create a learning environment for integrated courses. Teachers play the role of designer, giving careful consideration and arrangement to each aspect of the curriculum to support and promote meaningful learning, as shown in Figure 7.

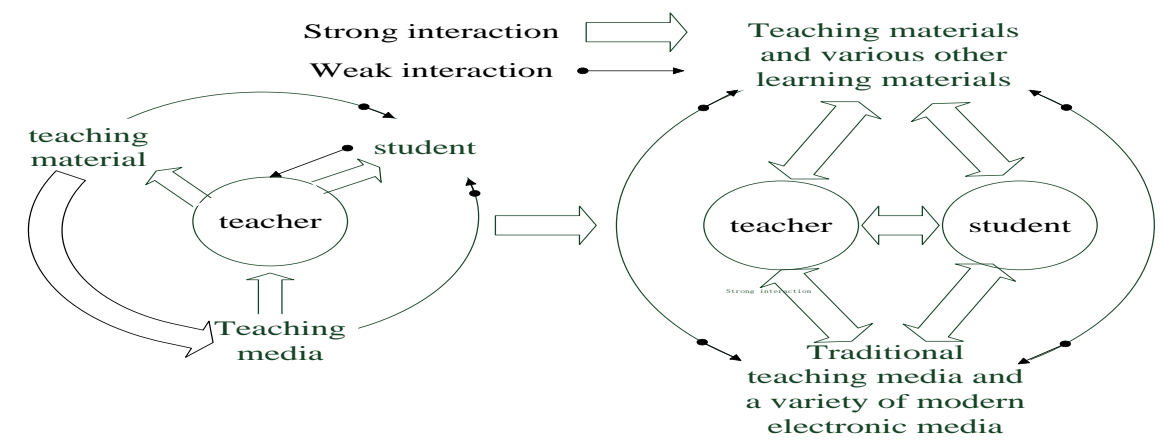

Figure 7. Dominant-subject teaching structure.

\section{Ecologicalization of English teaching}

Below we introduce the Student Center-Teacher Assistance mode, as shown in Figure 8. This model is an exploratory teaching model with strong self-feedback. By manipulating the information obtained by the computer (according to the needs and interests of their own learning), the learner conducts discovery learning through a series of learning activities such as observation, hypothesis, trial, verification, and adjustment. This kind of teaching mode may also be accompanied by the human-computer communication process, and the learner can also communicate with the teacher through the computer, requesting consultation or obtaining guidance.

In the specific classroom teaching, do not use these teaching modes separately. In practice, one or two modes can be used, or a combination of modes can be used. In addition, teachers can also establish the sixth and seventh modes with certain characteristics through practice. However, no matter what mode, teachers should use the above modes flexibly and comprehensively according to specific conditions (such as conditions, resources, student level, other conditions, etc.) to make the teaching elements and environment compatible and harmonious.

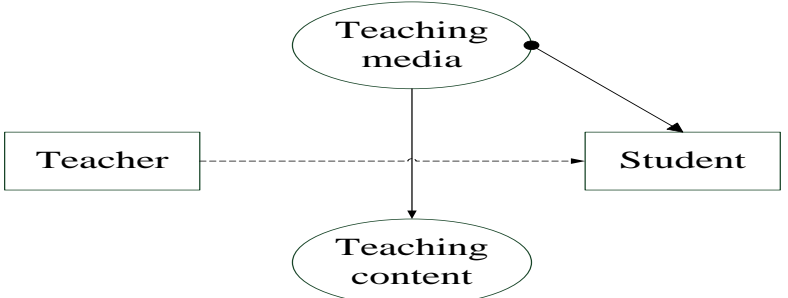

Figure 8. Student center - teacher assistance mode. 


\section{Conclusion}

After the integration of modern information technology and foreign language courses with computer network as the core, the teaching elements have changed, and many traditional elements (such as teaching materials, content, methods, etc.) have been replaced by new elements (such as multiple media, online content, technical methods, etc.) replaced. Changes in factors naturally break the balance of the traditional foreign language teaching system environment. The unbalanced teaching environment has led to many imbalances. As far as the law of foreign language teaching is concerned, if these disorders are ignored, the phenomenon of "disregarding" will occur. To find the causes and countermeasures of these disorders, it is difficult to rely solely on traditional teaching theories.

In this sense, the disorder of teaching has challenged traditional theories. It can be seen that to overcome the "rejection phenomenon" and reasonably explain the causes of the disorder, so that the teaching system maintains dynamic harmony, we should re-examine my foreign language teaching from an ecological perspective. In other words, it is necessary to examine the interrelationship, interaction and mutual adaptation of the internal elements of the teaching system with the surrounding environment according to the principle of ecology, study various teaching phenomena and their causes, and explore the characteristics and functions of the foreign language teaching ecology and its evolution. We say that foreign language teaching is a system. Actually, foreign language teaching consists of many interconnected and interacting parts (elements) that are composed of a certain level and structure and have specific functions. It is a kind of element in a certain space.

\section{References}

Arnal Wishnowski, L., Yu, C. T., Pear, J., Chand, C., \& Saltel, L. (2018). Effects of computer-aided instruction on the implementation of the MSWO stimulus preference assessment. Behavioral Interventions, 33(1), 5668. https://doi.org/10.1002/bin.1508

Ellis, R., Basturkmen, H., \& Loewen, S. (2012). Preemptive focus on form in the esl classroom. Tesol Quarterly, 35(3), 407-432. http://dx.doi.org/10.2307/3588029

Gan, C. L., \& Balakrishnan, V. (2014). Determinants of mobile wireless technology for promoting interactivity in lecture sessions: an empirical analysis. Journal of Computing in Higher Education, 26(2), 159-181. http://dx.doi.org/10.1007/s12528-014-9082-1

Hazavehei, S. M. M., Moonaghi, H. K., Moeini, B., Moghimbeigi, A., \& Emadzadeh, A. (2015). Investigating the key factors in designing a communication skills program for medical students: a qualitative study. Electronic Physician, 7(7), 1441-1448. http://dx.doi.org/ 10.19082/1441

Islam, R. (2017). Investigating factors that contribute to effective teaching-learning practices: EFL/ESL classroom context. English Language Teaching, 10(4), 15. http://dx.doi.org/10.5539/elt.v10n4p15 
Kreskey, D. D., \& Truscott, S. D. (2016). Is computer-aided instruction an effective tier-one intervention for kindergarten students at risk for reading failure in an applied setting. Contemporary School Psychology, 20(2), 142-151. https://doi.org/10.1007/s40688-015-0056-8

Lakin, J. M., Elliott, D. C., \& Liu, O. L. (2012). Investigating esl students' performance on outcomes assessments in higher education. Educational \& Psychological Measurement, 72(72), 734-753. http://dx.doi.org/ 10.1177/0013164412442376

Liao, Y. K. C. (2007). Effects of computer-assisted instruction on students' achievement in Taiwan: a metaanalysis. Computers \& Education, 48(2), 216-233. http://dx.doi.org/10.1016/j.compedu.2004.12.005

Nicole S, Jeremy R, Geneva H, \& Jennifer K. (2010). Investigating links from teacher knowledge, to classroom practice, to student learning in the instructional system of the middle-school mathematics classroom. Cognition \& Instruction, 28(3), 317-359. http://dx.doi.org/10.1080/07370008.2010.487961

Osagie, E. R., Wesselink, R., Blok, V., Lans, T., \& Mulder, M. (2016). Individual competencies for corporate social responsibility: A literature and practice perspective. Journal of Business Ethics, 135(2), 233-252. http://dx.doi.org/10.1007/s10551-014-2469-0

Rosales, R., Gongola, L., \& Homlitas, C. (2015). An evaluation of video modeling with embedded instructions to teach implementation of stimulus preference assessments. Journal of Applied Behavior Analysis, 48(1), 209-214.http://dx.doi.org/10.1002/jaba.174

Starrett, C., Doman, M., Garrison, C., \& Sleigh, M. (2015). Computational bead design: A pilot summer camp in computer aided design and 3D printing for middle school girls. In Proceedings of the 46th ACM Technical Symposium on Computer Science Education, 587-590. http://dx.doi.org/10.1145/2676723.2677303

Svirko, E., \& Mellanby, J. (2017). Teaching neuroanatomy using computer-aided learning: What makes for successful outcomes. Anatomical sciences education, 10(6), 560-569. http://dx.doi.org/10.1002/ase.1694

Zhang, X. (2017). Field composition and development trend of research hotspots of translation technology in China - based on co-word visualization analysis of relevant academic journals from CNKI published from 1999 to 2017. Theory and Practice in Language Studies, 7(12), 1210-1221. 